http://jmscr.igmpublication.org/home/ ISSN (e)-2347-176x ISSN (p) 2455-0450 crossref DOI: https://dx.doi.org/10.18535/jmscr/v8i6.112

\title{
Incidence of post operative complications after tonsillectomy in Chittagong Medical College Hospital
}

\author{
IGM Publication \\ Journal Of Medical Science And Clinical Research \\ An Official Publication of IGM Publication
}

Authors

Dr Md Mukhlesur Rahman ${ }^{*}$, Dr Mahmuda Begum², Dr Md Abbas Uddin ${ }^{3}$, Professor Dr Mujibul Hoque Khan ${ }^{4}$, Professor Dr Mostafa Mahfuzul Anwar

${ }^{1}$ Assistant Professor, Department of Otolaryngology- Head \& Neck Surgery, Chittagong Medical College, Chattogram, Bangladesh

${ }^{2}$ Assistant Professor, Department of Pathology, Chittagong Medical College, Chattogram, Bangladesh

${ }^{3}$ Associate Professor, Department of otolaryngology- Head \& Neck Surgery, BGC Trust Medical College, Chattogram, Bangladesh

${ }^{4}$ Head (Ex) of otolaryngology- Head \& Neck Surgery, Chittagong Medical College, Chattogram, Bangladesh

${ }^{5}$ Head of otolaryngology- Head \& Neck Surgery, Chittagong Medical College, Chattogram, Bangladesh

*Corresponding Author

\section{Dr Md Mukhlesur Rahman}

Assistant Professor, Department of otolaryngology- Head \& Neck Surgery, Chittagong Medical College, Chattogram Abstract
Background: Tonsillectomy is one of the most frequently undertaken procedures in otolaryngology, represents
approximately 20-40\% of surgical procedures performed in this field. Post operative complications following
tonsillectomy are generally rare, with post-tonsillectomy haemorrhage being one of the most common serious
complication. Episodes of post tonsillectomy haemorrhage are unpredictable and sometimes life threatening.
Materials and Methods: A prospective study was conducted department of otolaryngology-Head \& Neck Surgery
department, Chittagong Medical College Hospital, Chattogram from January 2018 to December 2018. We are
selected 211 patients undergoing tonsillectomy. Tonsillectomy was done by cold steel disscetion technique and
bipolar diathermy haemostasis.
Results: Maximum age group 107 (50.71\%) were from $11-20$ yrs. Maximum patients were male $130(61.61 \%)$ and
sex ratio of male:female 1.6:1. In this study commonest indication was recurrent tonsillitis $168(79.62 \%)$.
Complications that encountered after operation were haemorrhages both primary and secondary, $2(.94 \%)$ and
$5(2.36 \%)$ respectively. Local trauma was $8(3.79 \%)$ and local infection in tonsillar bed was $12(5.66 \%)$ cases.
Conclusion: Haemorrhage after tonsillectomy may occur in few occasions and more common in male patients.
Others complication like tonsillar bed infection\& trauma to lip, tongue, palate and post pharyngeal wall may occur
in significant number cases.

Keywords: Haemorrhage, Tonsillectomy.

\section{Introduction}

Tonsillectomy is one of the oldest and most common surgeries carried out by otolaryngologist. Post operative complications following tonsillectomy are generally rare, with post tonsillectomy haemorrhage being one of the most common serious complication ${ }^{1}$.
Tonsillectomy is one of the most frequently undertaken procedures in otolaryngology, representing approximately $20-40 \%$ of surgical procedures performed in this field ${ }^{2,3}$.

The previously reported risk factors for post tonsillectomy haemorrhage include sex, age, 
tonsillectomy indication, surgical technique and device and the skill level of the surgeon ${ }^{4}$.

Primary haemorrhage is haemorrhage occurring immediately as a result of an injury or surgery. Reactionary haemorrhage is haemorrhage within 24 hours after surgery and is usually caused by dislodgement of clot after resuscitation from general anaesthesia, normalization of blood pressure and vasodilatation. Reactionary haemorrhage may also result from technical failure such as slippage of ligature. Secondary haemorrhage is caused by sloughing off the wall of a vessel. It usually occurs 7-14 days after surgery and is precipitated by factors such as infection, Pressure necrosis or malignancy ${ }^{5}$.

Tonsillectomy is reported usually to be a simple and uncomplicated operation ${ }^{6}$. Some complication are secondary to anaesthesia which include myocardial instability, laryngeal trauma, aspiration of blood or mucous.

Besides anaesthetic cause, the most common factors responsible for death following tonsillectomy is haemorrhage either primary, reactionary or secondary specially when it remains unrecognizd and not treated ${ }^{7}$.

One of the most significant complication is post operative haemorrhage. A ten years retrospective study showed that seven of the 750 patients (.93\%) required a second general Anaesthesia to controll haemorrhage ${ }^{8}$.

\section{Aims and Objectives}

The aim and objectives are-

1) To find out the various post operative complications in tonsillectomy.

2) To find out the relation of post operative haemorrhage with age and sex.

\section{Materials and Methods}

Type of study: prospective study

Place of study: Department of otolaryngologyHead and Neck surgery, Chittagong Medical College Hospital, Chattogram.

Study period: January 2018 to December 2018.
Study Population: 211 patents admitted for tonsillectomy during the study period.

\section{Methods of Sampling and Pre-Operative Evaluation:}

Patients suspected of recurrenttonsilitis are evaluated properly by detailed history taking, demographic data, full otolaryngological symptoms, clinical and otolaryngological examination, past \& family history and relevant investigation (pre operative CBC and coagulation profile).

\section{Technique of Tonsillectomy:}

Cold steel dissection technique and Bipolar diathermy haemostasis under general anaesthesia.

\section{Data Collection:}

Relevant data were collected in a pro-designed data collection sheet for each of the patient with recurrent tonsillitis, who was undergone tonsillectomy.

\section{Operative Evaluation:}

Technique of tonsillectomy and possible operative complications.

\section{Post operative Manage:}

Every patient was treated with antibiotics (sefradin/cefuroxime, flucloxacillin), pain killer (diclofenac sodium and paracetamol), antihistamin, hydrogen-peroxide/ povidine iodine (1\%) mouth wash.

\section{Follow up evaluation:}

All the patients were assessed on the first, second, seventh, $14^{\text {th }}$ day and till the tonsillar fossa healed following the operation as follows:

a. History taking for post tonsillectomy bleedings

b. Full otolaryngological examination to detect evidence of infection in the tonsillar bed and the occurrence of post tonsillectomy bleeding.

\section{Inclusion Criteria}

Patients in whom the indication for tonsillectomy were included in the study. All patients above 4 years of age were selected and there was so upper age limit. 


\section{Exclusion Criteria}

Patient with no coagulation disorder, or with cardiovascular disorder, or those undergoing tonsillectomy as a part of palatoplasty for snoring and unilateral tonsillectomy for biopsy to exclude malignancy were exclude. Adenotonsillectomy or patients coming complication following tonsillectomy operation in outside of this hospital/ private clinics also excluded.

\section{Results}

The age range of 211 patients was 6-56 yrs, maximum $107(50.71 \%)$ were from 11-20 years which is shown in table 1.

Table-1: Age distribution of the cases $(n=211)$ :

\begin{tabular}{|l|c|c|}
\hline Age Group & Number of Cases & Percentage (\%) \\
\hline $0-10$ & 16 & 7.58 \\
\hline $11-20$ & 107 & 50.71 \\
\hline $21-30$ & 60 & 28.43 \\
\hline $31-40$ & 20 & 9.47 \\
\hline $41-50$ & 4 & 1.89 \\
\hline $51-60$ & 4 & 1.89 \\
\hline Total & 211 & 100 \\
\hline
\end{tabular}

Out of 211 patients 130 (31.61\%) were male and $81(38.38 \%)$ were female which is shown in table 2.

Table-2: Sex distribution of the study sample $(n=211)$ :

\begin{tabular}{|l|c|c|}
\hline Sex & No Cases & Percentage (\%) \\
\hline Male & 130 & 61.61 \\
\hline Female & 81 & 38.38 \\
\hline Total & 211 & 100 \\
\hline
\end{tabular}

Among the indications of operation, Recurrent tonsillitis was highest $168(79.62 \%)$, next to that was enlarge tonsil causing mechanical obstructive symptoms 30 (14.21\%).

Table-3: Indication of Tonsillectomy $(n=211)$

\begin{tabular}{|l|c|c|}
\hline Diagnosis & $\begin{array}{c}\text { Number of } \\
\text { patents }\end{array}$ & $\begin{array}{c}\text { Percentage } \\
(\mathbf{\%})\end{array}$ \\
\hline Recurrent tonsillitis & 168 & 79.62 \\
\hline $\begin{array}{l}\text { Pressure symptoms } \\
\text { (Dysphagia/ Dyspnea) }\end{array}$ & 30 & 14.21 \\
\hline $\begin{array}{l}\text { CSOM, OME where tonsil } \\
\text { was thought to be cause of } \\
\text { disease. }\end{array}$ & 11 & 5.21 \\
\hline H/O Quinsy & 2 & .94 \\
\hline Total & 211 & 100 \\
\hline
\end{tabular}

Complications that encountered after operation were haemorrhage both primary and secondary haemorrhage, $2(.94 \%)$ and $5(2.36 \%)$ respectively. Post operative local trauma is $8(3.79 \%)$ and local infection in tonsillar bed is $12(5.66 \%)$ which shown table 4.

Table 4: Incidence of post operative complications of tonsillectomy $(n=211)$

\begin{tabular}{|l|c|c|}
\hline Complications & $\begin{array}{c}\text { Number of } \\
\text { patent }\end{array}$ & $\begin{array}{c}\text { Percentage } \\
(\mathbf{\%})\end{array}$ \\
\hline Primary haemorrhage & 2 & .94 \\
\hline Reactionary haemorrhage & 00 & 00 \\
\hline Secondary haemorrhage & 5 & 2.36 \\
\hline $\begin{array}{l}\text { Local infection in } \\
\text { tonsillar bed }\end{array}$ & 12 & 5.66 \\
\hline $\begin{array}{l}\text { Injury to lip, tongue, gum, } \\
\text { post pillar of tonsil, teeth, } \\
\text { pharynx. }\end{array}$ & 8 & 3.79 \\
\hline Total & & \\
\hline
\end{tabular}

Out of 7 cases of post operative haemorrhage, male patients were $4(57.14 \%)$ and female patients were $3(42.85 \%)$ which is shown in table 5.

Table 5: Sex distribution of patient with post operative haemorrhage $(n=7)$

\begin{tabular}{|l|c|c|}
\hline Gender & Number of pt & Percentage (\%) \\
\hline Male & 4 & $57.14 \%$ \\
\hline Female & 3 & $42.85 \%$ \\
\hline Total & 7 & 100 \\
\hline
\end{tabular}

\section{Discussion}

Tonsillectomy is probable the most common operation performed by an otolaryngologist. One of the most significant complications are most operative haemorrhage. In this study, we tried to find out the incidence of primary, reactionary, secondary haemorrhage after tonsillectomy. In our study maximum age group 107(50.71\%) were from 11-20 yrs age group followed by 60 (28.43\%) were from 21-30 yrs age group. Study done by Kamal MS et al showed maximum age group within 11-20 years (50\%) followed by 21$30 \mathrm{yrs}(26.78 \%)$ which is nearer to our study ${ }^{9}$.

Sex distribution of the study sample showed 130 $(61.61 \%)$ were male and $81(38.30 \%)$ were female. A study done by Ahmed EBM, Ahmed FBM ${ }^{10}$ showed male $63 \%$ and female $37 \%$ which is nearer to our study. Most common indication of tonsillectomy was recurrent tonsillitis 168 
(79.62\%) wich is in accordance with the findings of Joarder $\mathrm{AH}^{11}$.

In our study, post operative haemorrhage was $3.30 \%$, among them primary haemorrhage was $.94 \%$ and secondary haemorrhage was $2.36 \%$. There was no reactionary haemorrhage. The incidence of post operative haemorrhage in this study was slightly higher than the study of Grysdale WS et $\mathrm{al}^{12}(2.15 \%)$ and nearly similar to study done by Kumar Pronoy ${ }^{13}(3.0 \%)$ and study done by Chowdhury AQ et $\mathrm{al}^{14}(3 \%)$. Study done by QureshiS et al ${ }^{15}$ showed primary haemorrhage was $0.6 \%$ and secondary haemorrhage was $3.7 \%$ which is nearer to our study.

In our study post operative tonsillar bed infection was $12(5.66 \%)$ which is very close to the study of Rafiquzzaman $\mathrm{M}^{16}$ and Kumar Pronoy ${ }^{13}$ they showed 5\% tonsillar bed infection. In our study, trauma to upper lip, tongue, teeth, gum, post pillar of tonsil and post pharyngeal wall was $3.79 \%$. Study done by Chowdhury AQ et $\mathrm{al}^{14}$ and Kumar Pronoy $^{13}$ showed injuries was $4 \%$ and $3 \%$ respectively.

In relation to sex, out of 7 cases of the post operative haemorrhage $4(57.14 \%)$ cases male and 3 cases $(42.85 \%)$ were female, accordance with Author ${ }^{14,16}$.

\section{Conclusion}

From this study we can conclude that haemorrhage after tonsillectomy may occur in few occasions and it is more common in male patients. The other complications like tonsillar bed infection \& trauma to lip, tongue, palate and post pharyngeal wall may occur in a significant number of cases. However the results of the present study may not be the representative of overall situation as it was carried out with a limited number of patents in a limited span of time.

\section{Disclosure}

All the authors declared no competing interest.

\section{References}

1. Hesham Negm, Ahmed Atef, Hesham Lasheen, Ahmed A Kemel Khaled Azooz, Osama Ethoussainy. Factors affecting secondary post tonsillectomy haemorrhage: a case controll study. 2017; 3(1): 50-55.

2. Ahsan F, Rashid H, Eng C. Is secondary haemorrhage after tonsillectomy in adult an infective condition? Objective measure of infection in a prospective cohort. Clinotolaryngol. 2007; 32(1) : 24-7.

3. Evans AS, Khan AM, Young D. Assessment of secondary haemorrhage rates following adult tonsillectomy- a telephone survey and literature review. Clinotolaryngol Allied Sci.2003; 28(6):489-91.

4. Tomkison A, de Martin S, Gilchrest CR, Temple M. Instrumentation and patient characteristics that influence post operative haemorrhage rates following tonsil and adenoid surgery. Clin otolaryngology.2005; 30:338-346.

5. Williams NS, Bultrode CJK, O'connell PR (editors). Baily and Love's short practice of surgery, $26^{\text {th }}$ edition. London, Hodder Arnold .2013, 19.

6. Tami TA, Barket GS, Laylor R. Post tonsillectomy bleeding an evaluation of risk factors, Laryngoscope.1987; 97:422429.

7. Tale N. Deaths from tonsillectomy (Letter). Lancet ii: 1963; 1090-1091

8. Schroeder WA Jr. Post tonsillectomy Haemorrhage: A ten year retrospective study. MO Med.1995; 92(9): 592-595.

9. Kamal MS, Farzana R, Humayun AHMP, Hoque AHMZ, Rahman MM. Incidence of haemorrhage after tonsillectomy. Bangladesh J otorhinology. 2012; 13(1) : 55-58

10. Ahmed EBM, Ahmed FBM. Posttonsillectomy haemorrhage in Bipolar diathermy versus conventional technique. 
Clinical Medicine Research .2015; 4(6): 189-194

11. Joarder AH. Post tonsillectomy complications: A study of 50 cases (Dissertation) Dhaka, Bangladesh college of physicians and surgeons 1990.

12. Grysdale WS, Russel D. Complications of tonsillectomy and adenoidectomy in 9409 children observed over night. Can Med Association J. 1986; 135(10): 1139-1142.

13. Kumar pronoy, An audit of the complications of paediatric tonsillectomy, adenoidectomy and adenotonsillectomy in IPGMR (Former) and DMCH Dhaka (a study of 100 cases) Dissertation Dhaka, Bangladesh college of physicians and surgeons 1997.

14. Chowdhury AQ, Majumder D, Nath JD. Complications of tonsillectomy, Adenotonsillectomy and Adenoidectomy in Chittagong Medical College Hospital, Chattogram. Chattogram Maa-O-Shishu Hospital Medical Journal. 2014; 13(2): 47.

15. Qureshi S, Tirmizi S, Sulehri A. Occurence of post-tonsillectomy haemorrhage in paediatric age group. Pakistan Journal of otolaryngology. 2010; 26:56-57.

16. Rafiquzzaman M. Prophylactic single dose of antibiotic in tonsillectomy, study of 100 cases (Dissertation) Dhaka, Bangladesh College of Physicians and Surgeons 1994. 